Original Article

\title{
IN VITRO AND IN SILICO ANTIBACTERIAL ACTIVITY OF 1.5-BIS (3'-ETHOXY-4'- HYDROXYPHENYL)-1-4-PENTADIENE-3-ONE
}

\author{
AGUS PURWANGGANA1 ${ }^{1}$, ESTI MUMPUNI ${ }^{*}$, ESTI MULATSARI ${ }^{1}$
}

${ }^{1}$ Faculty of Pharmacy, University of Pancasila, Srengseng sawah, Jagakarsa, South of Jakarta, Indonesia 12640

Email: esti_mumpuni@yahoo.com

Received: 05 Feb 2018 Revised and Accepted: 02 Apr 2018

\begin{abstract}
Objective: The main objective of this research were screened in vitro and in silico of 1,5-bis (3'-ethoxy-4'-hydroxyphenyl)-1,4-pentadiene-3-one as potential antibacterial agents.

Methods: The in vitro antibacterial study was carried against Staphylococcus aureus, Staphylococcus epidermidis (gram positive) and Escherichia coli, Salmonella thypi (gram negative) using broth dilution method to determine Minimum Inhibitory Concentration (MIC), disc diffusion method to determine the diameter of inhibition zone. In silico antibacterial study was carried using computational software Protein-Ligand ANT System (PLANTS), computational docking was carried using receptor with Protein Data Bank (PDB) file 3MZD. The structures were optimized prior docking using YASARA, and MarvinSketch. The results of antibacterial testing were compared to two positive control drugs i. e amoxicillin and cefadroxil.

Results: In vitro evaluation showed that 1,5-bis (3'-ethoxy-4'-hydroxyphenyl)-1,4-pentadiene-3-one has a better antibacterial activity than amoxicillin and cefadroxil with a Minimum Inhibitory Concentration (MIC) of $0.15 \mathrm{ppm}$ and diameter of inhibition zone of $11.27 \pm 0.31,11.35 \pm 0.39$, $11.25 \pm 0.33$, and $11.05 \pm 0.45 \mathrm{~mm}$ in Staphylococcus aureus, Staphylococcus epidermidis, Escherichia coli, and Salmonella thypi, respectively. These results in line with in silico evaluation that showed 1,5-bis (3'-ethoxy-4'-hydroxyphenyl)-1,4-pentadiene-3-one has more negative docking score than amoxicillin, cefadroxil, and cloxacillin acyl as a native ligand on the 3MZD receptor.
\end{abstract}

Conclusion: This results obtained in this research work were 1,5-bis (3'-ethoxy-4'-hydroxyphenyl)-1,4-pentadiene-3-one compound potential as an antibacterial agent.

Keywords: 1,5-bis (3'-ethoxy-4'-hydroxyphenyl)-1,4-pentadiene-3-one, Antibacterial, In silico, In vitro

(C) 2018 The Authors. Published by Innovare Academic Sciences Pvt Ltd. This is an open access article under the CC BY license (http://creativecommons.org/licenses/by/4.0/) DOI: http://dx.doi.org/10.22159/ijpps.2018v10i5.25143

\section{INTRODUCTION}

Bacteria were very small and harmful organism, some bacteria could cause various types of infectious diseases such as typhoid [1], common cold [2], influenza [3], pneumonia [4], malaria [5], amebiasis [6], syphilis and AIDS [7]. Bacteria may be innate resistant or acquire resistance to one or few classes of antimicrobial agents. Bacterial resistance to antimicrobial drugs was an increased health and economic problem [8] so, developed a new antibacterial agent was so important. An antibacterial agent from the natural material like curcumin has been developed [9-11].

Curcumin-related studies were increasingly evolving with more modification of curcumin structure and its activity test as antibacterial. Some studies related to curcumin modification as an antibacterial include curcumin modification into mono-carbonyl analogue curcumin [12], curcumin biconjugate [13], heterocyclic moiety curcumin [14], Curcuminaniline Functionalized Nanoform [15]. Most of the curcumin modification reported could enhance the antibacterial activity.

One of the other curcumin modification compounds was 1,5-bis (3'ethoxy-4'-hydroxyphenyl)-1,4-pentadiene-3-one with the molecular formula $\mathrm{C}_{21} \mathrm{H}_{22} \mathrm{O}_{5}$ (fig. 1). The 1,5-bis (3'-ethoxy-4'-hydroxyphenyl)1,4-pentadiene-3-one compound has been successfully synthesized with aldol condensation method [16,17]. Activity tested of 1,5-bis (3'-ethoxy-4'-hydroxyphenyl)-1,4-pentadiene-3-one as antioxidants showed better ability than curcumin. The anti-inflammatory activity of 1,5-bis (3'-ethoxy-4'-hydroxyphenyl)-1,4-pentadiene-3-one has been performed and indicated a better than curcumin [18]. 1,5-bis (3'-ethoxy-4'-hydroxyphenyl)-1,4-pentadiene-3-one was also expected to have a good antibacterial activity. So, this study aimed to test antibacterial activity of 1,5-bis (3'-ethoxy-4'-hydroxyphenyl)1,4-pentadiene-3-one using in silico and in vitro evaluation. In vitro evaluation were used for several types of bacteria on a gram- positive group (Staphylococcus aureus, Staphylococcus epidermidis), and gram-negative group (Escherichia coli, Salmonella Typhii). The in silico evaluation was performed using molecular docking on receptor PDB ID 3MZD. This antibacterial activity test refers to the inhibition of the D-Alanil-D-Alanin transport enzyme (D-Alanil-DAlanin decarboxylase (DACA)) on peptidoglycan formation on the bacterial cell wall, so in this study used $\beta$-lactam group antibiotic such as amoxicillin and cefadroxil as a positive control. The $\beta$-lactam group antibiotics were produced most widely and were used as antibacterial drugs in the world, and have been used since the initial appearance of clinical trials in $1941[19,20]$.<smiles>CCOc1cc(/C=C/C(=O)/C=C/c2ccc(O)c(OC)c2)ccc1O</smiles>

Fig. 1: Chemical Structure of 1,5-bis (3'-ethoxy-4'hydroxyphenyl)-1,4-pentadiene-3-one

\section{MATERIALS AND METHODS}

\section{Chemicals}

The following chemicals and materials were used: Ethyl Vanilin (3ethoxy-4-hydroxybenzaldehyde) (Sigma Aldrich), glacial acetic acid (Mallincordt Chemical), Chloric acid (Mallincordt Chemical), acetone (Mallincordt Chemical), chloroform (Mallincordt Chemical), ethyl acetic (Mallincordt Chemical), methanol (Mallincordt Chemical), metabisulfit (Mallincordt Chemical), 96\% ethanol (Mallincordt Chemical), aquadest. All other ingredients used were of analytical grade. 


\section{Culture media}

Nutrient agar (NA), peptone broth, the test bacteria used in this study were a clinical isolate of Staphylococcus aureus (ATCC 6538), Staphylococcus epidermidis (ATCC 12228), Escherichia coli (ATCC 25922), and Salmonella thypi (ATCC 14028) supplied by the Departement of Microbiology Medical Faculty, University of Indonesia.

\section{Instruments}

Allihin condensor, Flat-bottom flask, magnetic stirer, volume pipete, micropippete Eppendorf, chromatograph vessel, Silica gel plate $\mathrm{GF}_{254}$, glass tools (pyrex), filter paper, Spatula, parchment paper, petri dish Spectrophotometer ultraviolet-visible (Shimadzu, UV 1601), Spectrophotometer Fourier Transform-Infra Red (Shimadzu FT-IR 8400S), Spectrophotometer Nuclear Magnetic Resonance (NMR) (JEOL, JNM ECA-500), Gas Chromatography-Mass Spectrometer (Agilent Technologies 6890 Gas Chromatograph and 5972 mass selective detector), Thin Layer Chromatography (TLC), Densitometer (Camag TLC Scanner 3), Melting range finder (BUCHI 540), Analytical scales (Mettler MT5), Stir Plate and magnetic stirer, Allihn condensor, capillary tube, Oven Microwave (Cevilla CMG 003.21L).

\section{Experimental method}

Synthesis of 1,5-bis (3'-ethoxy-4'-hydroxyphenyl)-1,4-pentadiene-3one was carried out using aldol condensation reaction. Methanol and acetone in the flat flask connected to Allihin condenser at room temperature were stirred using magnetic stirrer for $5 \mathrm{~min}$, ethyl vanillin and concentrated $\mathrm{HCl}$ was added until $\mathrm{pH}$ value of $2-3$, stir for $2 \mathrm{~h}$ at $500 \mathrm{rpm}$. exposure to microwave radiation over time, observed using Thin Layer Chromatography (TLC) and densitometry method in Silica gel $\mathrm{GF}_{254}$ was eluted with chloroform-ethyl acetate (5:1). The yield as aromatic odor, yellow and brownish green color, m. p: (95.5-96.4 $\left.{ }^{\circ} \mathrm{C}\right)$, FTIR (KBr): $1676.99 \mathrm{~cm}^{-1}(\mathrm{C}=0), 1578.63 \mathrm{~cm}^{-}$ ${ }^{1}(\mathrm{C}=\mathrm{C}$ is conjugated with the aromatic core $), 3500-2500 \mathrm{~cm}^{-1}(\mathrm{O}-\mathrm{H}$ group), 2979.82 and $2931.60 \mathrm{~cm}^{-1}(\mathrm{C}-\mathrm{H}), 654.79$ and $838.98 \mathrm{~cm}^{-1}$ (C$\mathrm{H}$ aromatic ring substitution). Thus, the aldehyde group in ethyl vanillin had shifted to the ketone group in the synthesis compounds. ${ }^{13} \mathrm{C}$ NMR and ${ }^{1} \mathrm{H}$ NMR Analysis: chemical shift signal at $\delta \mathrm{c}$ 15.01 indicates the carbon at methyl group has a high magnetic fields and $\delta_{c} 64.8$ indicate the presence of carbon at $\mathrm{O}-\mathrm{CH}_{2}$ group. Then 6 carbons on the benzene ring each $\delta_{\mathrm{C}} 110.8,114.5,123.3$, $127.5,146.2$, and 148.4 . Two carbon atoms on the olefinic group at $\delta_{\mathrm{C}} 143.4$ and 123.4 , while the carbon to the carbonyl group at $\delta_{\mathrm{C}}$ 188.9. ${ }^{1 \mathrm{H} N M R}$ spectrum identification for 1,5-bis (3'-ethoxy-4'hydroxyphenyl)-1,4-pentadiene-3-one compound integral spectrum shows the chemical compound has 11 protons. In regions of high field is at $\delta_{\mathrm{H}} 1.49$ (triplet) predicted the existence of protons of methyl groups $\left(-\mathrm{CH}_{3}\right)$. Protons on- $\mathrm{CH}_{2}$ which neared by- $\mathrm{CH}_{3}$ group are at chemical shifts $\delta_{H} 4.16$ (quartet), while $\delta_{H} 5.94$ (singlet) showed the proton at the $\mathrm{OH}$ group. At $\delta_{\mathrm{H}} 6.94 \sim 6.95$ (doublet $J_{\mathrm{Hz}} 5$ ); $7.09 \sim 7.10(\mathrm{~s}) ; 7.16 \sim 7.18$ (doublet $J_{\mathrm{Hz}} 10$ ) were a typical area for protons in benzene, which was the value of J coupling indicates the ortho position. While the characteristics of the proton on olefinic groups were at $\delta_{\mathrm{H}} 6.89 \sim 6.93$ (doublet $J_{\mathrm{Hz}} 20$ ) and $7.64 \sim 7.67$ (doublet $J_{\mathrm{Hz}} 15$ ) showed the $\mathrm{H}$ substituent in the transposition [17].

\section{In silico antibacterial test}

Preparation of proteins and ligands has done using YASARA software. PDB ID 3MZD have been downloaded from http://www.rcsb.org/pdb/explore/explore.do?structureld=3mzd loaded on YASARA worksheets, proteins and native ligand are separated and saved with file names protein.mol ${ }^{2}$ and ref_ligand. mol2. Native ligand and new ligands (1,5-bis (3'-ethoxy-4'hydroxyphenyl)-1,4-pentadiene-3-one, amoxicillin, cefadroxil) are continuously prepared to form conformations using MarvinSkecth and saved with file name ligand.mol ${ }^{2}$. The docking protocol validation is performed by calculating the Root Mean Square Deviation (RMSD) values between the native ligand (cloxacillin acyl) of PDB ID 3MZD with the confirmation of the docked ligand. Docking protocol is considered good and can be used for the further docking process if it has a value of $2 \AA$., closer to 0 considered the alignment is better. This validation result used to configure the plantsconfig. file. The docking process has done using standard procedure of molecular docking using PLANTS operating system [21, 22], validated protocol (plantsconfig. file), ref_ligand.mol ${ }^{2}$, protein.mol ${ }^{2}$, and ligand. $\mathrm{mol}^{2}$, and ligand. $\mathrm{mol}^{2}$ prepared as input data. Docking process has done by typing commands on cmd worksheet. The PLANTS application will read the validated protocol and start the docking process. Docking process obtained docking scores as output data that showed the energy of the ligand in binding to the target protein. The more negative of docking scores, the affinity of the ligand binding to the protein was stronger.

\section{In vitro antibacterial test}

\section{Measurement of minimum inhibitory concentration (MIC)}

The 1,5-bis (3'-ethoxy-4'-hydroxyphenyl)-1,4-pentadiene-3-one, amoxicillin and cefadroxil were screened in vitro for determined Minimum Inhibitory Concentration (MIC) using the broth dilution method. Staphylococcus aureus (ATCC 6538), Staphylococcus epidermidis (ATCC 12228), Escherichia coli (ATCC 25922), and Salmonella thypi (ATCC 14028). Bacterial strains were cultivated separately in nutrient agar plates. The bacterial inoculums $[0.25$ optical density (OD)) was prepared and incubated for 24h [23]. The 1,5-bis (3'-ethoxy-4'-hydroxyphenyl)-1,4-pentadiene-3-one, prepared in serially concentration 0,$30 ; 0.25 ; 0.20 ; 0.175 ; 0.15 ; 0.125 ; 0.10$ $\mathrm{mg} / \mathrm{l}$. The amoxicillin and cefadroxil concentration prepared in serially concentration $32 ; 16 ; 8 ; 4 ; 2 ; 1 ; 0.5 ; 0.25 \mathrm{mg} / \mathrm{l}$. All of them prepared in test tubes. The bacterial inoculums were added each 0.5 $\mathrm{ml}$ into the test tubes then incubated at $35-37{ }^{\circ} \mathrm{C}$ for $18-24 \mathrm{~h}$. The Minimum Inhibitory Concentration (MIC) for bacteria was determined as the lowest concentration of the compound inhibiting the visual growth of the test cultures on the agar plates.

\section{Measurement of the diameter of inhibition zone}

The diameter of inhibition zone was performed using Kirby-Bauer disc diffusion method. The bacterial inoculums $(0.25$ optical density (OD)) inserted into each sterile petri dish $0.5 \mathrm{ml}$, added $15-20 \mathrm{ml}$ of Nutrient Agar (NA). Then homogenized and solidified the bacteria suspension and Nutrient Agar (NA) medium at room temperature for 15-30 min. After the solidified, inserted solution of EHP with various concentrations into the petri dish. Then incubated at 35-37 ${ }^{\circ} \mathrm{C}$ for 24h [23]. Measured clear zone formed with units of millimetres $(\mathrm{mm})$. The same procedure as determined by the diameter of the inhibitory zone of amoxicillin and cefadroxil.

\section{RESULTS AND DISCUSSION}

The synthesis of 1,5-bis (3'-ethoxy-4'-hydroxyphenyl)-1,4pentadiene-3-one compound was prepared based on the $\alpha, \beta$ disconnect analysis on target molecules by methods developed by Stuart Warren (2008) (fig. 2) [24].

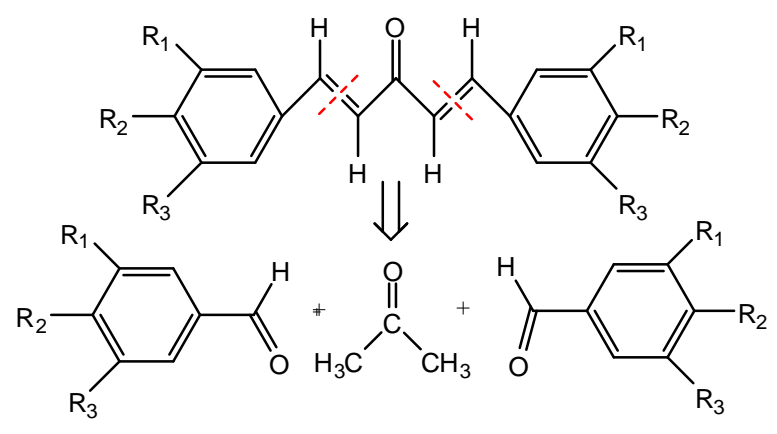

Fig. 2: $\alpha, \beta$ disconnect analysis on EHP

Preparation of 1,5-bis (3'-ethoxy-4'-hydroxyphenyl)-1,4-pentadiene3 -one by aldol condensation reaction (fig. 3 ). The mechanism of the aldol condensation reaction involves aldehyde and ketone compounds. The ketone group forms an enol compound as the nucleophile with the aid of an acid catalyst, the anion is reversibly convertible to the carbonyl group of the aldehyde molecule. This 
aldehyde molecule previously undergoes a protonation of its carbonyl group, producing a $\beta$-hydroxy carbonyl compound. Beginning with a nucleophile attack on carbon atoms from carbonoxygen double bonds, it occurs because carbon has a positive charge.
The adduction reaction takes place, followed by a dehydration process and produces a carbonyl $\alpha, \beta$ unsaturated. The FTIR, ${ }^{13} \mathrm{CNMR},{ }^{1 \mathrm{H} N M R}$ and elemental analysis were consistent with the assigned structure.

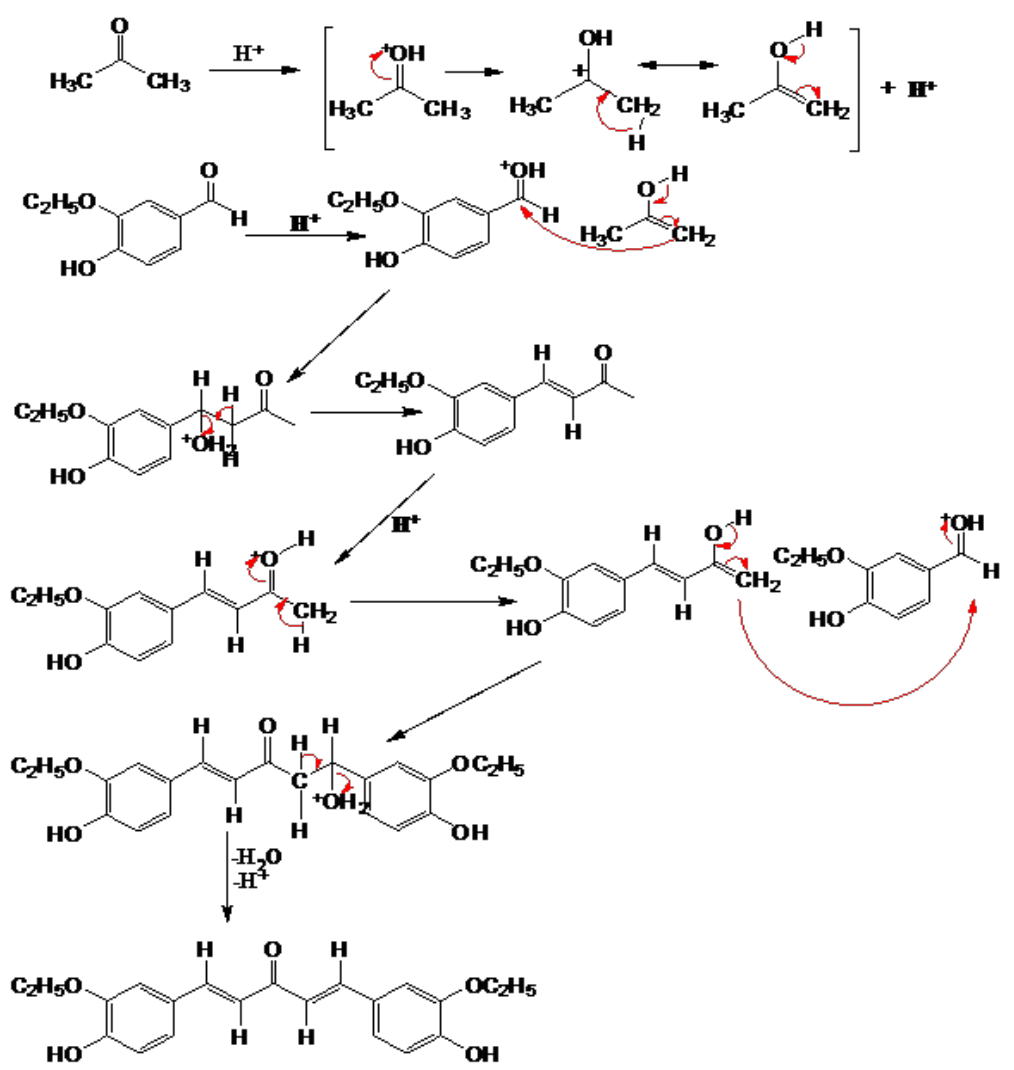

Fig. 3: The mechanism of the aldol condensation reaction involves aldehyde and ketone compounds

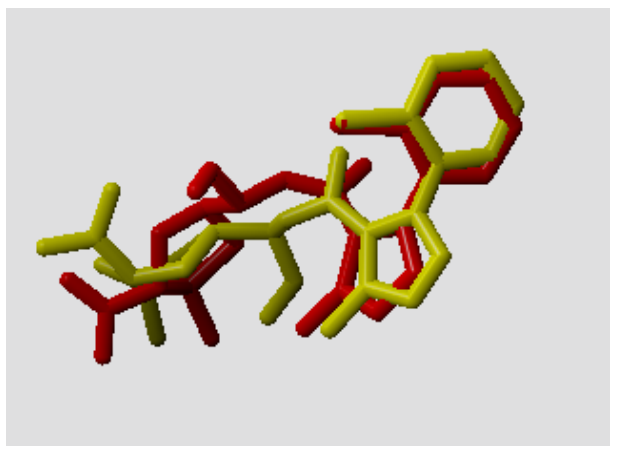

Fig. 4: Alignment of reference ligand (red) and docked ligand (yellow)

\section{In silico evaluation of 1,5-bis (3'-ethoxy-4'-hydroxyphenyl)-1,4- pentadiene-3-one as antibacterial}

In silico evaluation of 1,5-bis (3'-ethoxy-4'-hydroxyphenyl)-1,4pentadiene-3-one compound as antibacterial was done by molecular docking of 1,5-bis (3'-ethoxy-4'-hydroxyphenyl)-1,4pentadiene-3-one compound to the $\beta$-lactam receptor, referred to the stage of peptidoglycan formation which one of its starting material was D-Alanil-D-Alanine. D-Alanil-D-Alanin transport enzyme was D-Alanil-D-Alanine decarboxylase (DACA), this enzyme was already available in Protein Data Bank (PDB) file with PDB ID 3MZD. Cloxacillin acyl was bound in PDB ID 3MZD as an inhibitor or native ligand.
Validation of molecular docking protocol was performed to ensure that the receptor was suitable for use in molecular docking process. The validation process obtained Root Mean Square Deviation (RMSD) value of $1.9553 \AA$. Root Mean Square Deviation (RMSD) value less than $2 \AA$ indicated that the docking protocol with PDB. ID 3MZD receptor was feasible to be used for docking process of 1,5-bis (3'ethoxy-4'-hydroxyphenyl)-1,4-pentadiene-3-one as an antibacterial agent and the alignment between the reference ligand and the conformation of the docked ligand was very good (fig. 4) [25].

Docking process of 1,5-bis (3'-ethoxy-4'-hydroxyphenyl)-1,4pentadiene-3-one with PDB ID 3MZD receptor obtained docking score of-91.5305, it was much lower than the docking score of cloxacillin acyl which is native ligand (-81.9278). It was possible that 1,5-bis (3'-ethoxy-4'-hydroxyphenyl)-1,4-pentadiene-3-one becomes potential antibacterial compounds. Comparing with amoxicillin and cefadroxil, the antibacterial activity of the 1,5-bis (3'ethoxy-4'-hydroxyphenyl)-1,4-pentadiene-3-one is better, it showed by docking score of amoxicillin $(-87.6313)$ and the cefadroxil (85.4935) greater than docking score of 1,5-bis (3'-ethoxy-4'hydroxyphenyl)-1,4-pentadiene-3-one. The lower docking score was the better stability level between ligand and receptor so the stronger bonds will be formed. The negative value of binding energy change $(\Delta \mathrm{G})$ reveals that the binding process is spontaneous it could fit well in the binding pocket receptor forming most stable drug receptor energetically [26]. Larger the negative value of binding energy, greater the chemical be accepted as a drug [27]. The position of ligands in the binding pocket of PDB ID 3MZD receptor showed in (fig. 5), hydrophobic site show in green areas and hydrogen bond in purple areas. 


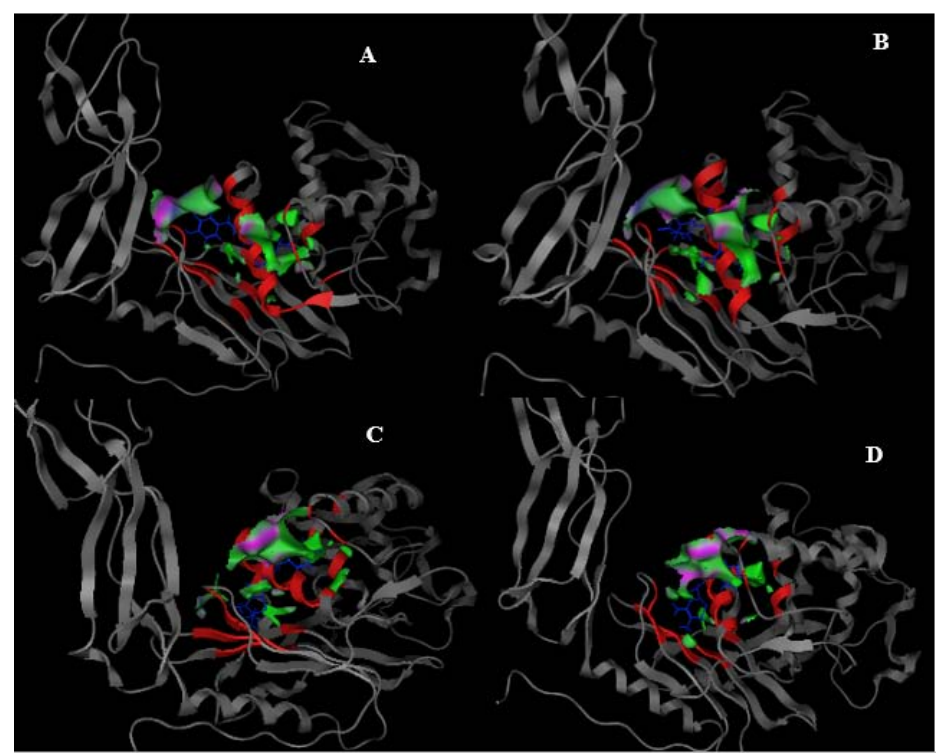

Fig. 5: Position of ligand (blue) (A) 1,5-bis (3'-ethoxy-4'-hydroxyphenyl)-1,4-pentadiene-3-one, (B) Cloxacilin acyl, (C) Amoxicillin, (D) Cefadroxil in the binding pocket (red) of PDB ID 3MZD protein

The amino acid residues on the active site of the PDB ID 3MZD receptor that formed the hydrogen bond with the cloxacillin acyl there were 4 i. e ALA171, ARG174, ILE173, and LEU172. The oxygen on carbonyl group of cloxacillin acyl ligand has bonded with hydrogen in the amino group of LEU172 (2.2 $\AA$ ) and ALA171(2 Å) while the other oxygen on carbonyl group has bonded with the hydrogen atoms on the amino group of ILE173 (1.7 $\AA$ ) and ARG174 (1.8 $\AA$ ). Amino acid residues in the PDB ID 3MZD receptor binding sites that formed hydrogen bonds with 1,5-bis (3'-ethoxy-4'-hydroxyphenyl)-1,4-pentadiene-3-one were included LEU167 and ILE173. The oxygen on hydroxy group of 1,5-bis (3'-ethoxy4'-hydroxyphenyl)-1,4-pentadiene-3-one has bonded with hydrogen in the amino group of LEU167 (2.5 ^) while the oxygen on carbonyl group has bonded with hydrogen in amino group of ILE173 (1.7 ̊). In amoxicillin hydrogen bonds were formed between oxygen on carbonyl group with hydrogen on amino group of LEU172 (1.6 ̊) while in cefadroxil, hydrogen bonds were formed by hydrogen of the methyl group with the oxygen on LEU167 (2.4 $\AA$ ) and the oxygen on carbonyl group with the hydrogen on the amino group of ILE173 (1.7 $\AA)$ and SER227 (2.2 A) (fig. 6). The amino acid residues affected the bond on the PDB ID 3MZD receptor, the interaction of the ligand and PDB ID 3MZD receptor may occur due to hydrogen bonding, Van Der Walls bonding, and electrostatic interactions [23].
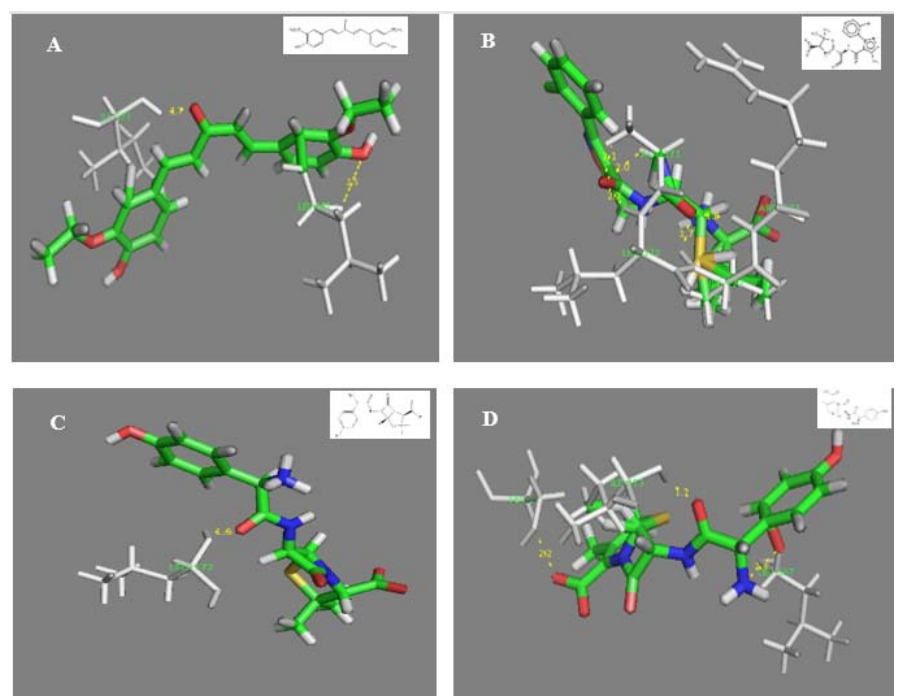

Fig. 6: Hydrogen bond (yellow) of (A) 1,5-bis (3'-ethoxy-4'-hydroxyphenyl)-1,4-pentadiene-3-one, (B) Cloxacilin acyl, (C) Amoxicillin, (D) Cefadroxil in the binding site of 3MZD protein

Table 1: Minimum inhibitory concentration (ppm)

\begin{tabular}{lllll}
\hline $\begin{array}{l}\text { Test } \\
\text { compound }\end{array}$ & $\begin{array}{l}\text { Staphylococcus } \\
\text { aureus (ATCC 6538) }\end{array}$ & $\begin{array}{l}\text { Staphylococcus epidermidis (ATCC } \\
\mathbf{1 2 2 2 8})\end{array}$ & $\begin{array}{l}\text { Escherichia coli (ATCC } \\
\mathbf{2 5 9 2 2} \text { ), }\end{array}$ & $\begin{array}{l}\text { Salmonella thypi (ATCC } \\
\mathbf{1 4 0 2 8} \text { ). }\end{array}$ \\
\hline EHP & 0.15 & 0.15 & 0.15 & 0.15 \\
Amoxicillin & 2 & 4 & 2 & 1 \\
Cefadroxil & 1 & 8 & 4 & 2 \\
\hline
\end{tabular}


In vitro evaluation of 1,5-bis (3'-ethoxy-4'-hydroxyphenyl)-1,4pentadiene-3-one as antibacterial

\section{Minimum inhibitory concentrations (MIC)}

Evaluation of Minimum Inhibitory Concentration (MIC) aimed to determine the lowest concentration of a test compound in inhibiting the growth of bacteria (table 1).

The 1,5-bis (3'-ethoxy-4'-hydroxyphenyl)-1,4-pentadiene-3-one was inhibited test bacteria with a lower concentration than amoxicillin and cefadroxil. It's could inhibit test bacterias at minimum inhibitory concentrations (MIC) of $0.15 \mathrm{ppm}$ for all test bacterias. It was indicated that the concentration of 1,5-bis (3'-ethoxy-4'hydroxyphenyl)-1,4-pentadiene-3-one has bacteriostatic properties. While the Minimum Inhibitory Concentration (MIC) of amoxicillin obtained at $2 \mathrm{ppm}$ for Staphylococcus aureus (ATCC 6538), $4 \mathrm{ppm}$ for Staphylococcus epidermidis (ATCC 12228), 2 ppm for Escherichia coli (ATCC 25922), and $1 \mathrm{ppm}$ for Salmonella thypi (ATCC 14028). The minimum inhibitory concentrations of cefadroxil obtained at $1 \mathrm{ppm}$ for Staphylococcus aureus (ATCC 6538), $8 \mathrm{ppm}$ for Staphylococcus epidermidis (ATCC 12228), 4 ppm for Escherichia coli (ATCC 25922), and $2 \mathrm{ppm}$ for Salmonella thypi (ATCC 14028). Mechanism of amoxicillin and cephalosporins as antibiotics inhibited the synthesis of microbial cell walls, both active antibiotics against gram-positive and gram-negative, but the antimicrobial spectra of each derivate were varied [11]. The differences of Minimum Inhibitory Concentration (MIC) value of both antibiotics caused by amoxicillin is the prototype of aminopenicillin group with wide-spectrum that can inhibit bacteria from the gram-positive and gram-negative group. While cefadroxil was the first generation of cephalosporins, the cephalosporin group was broad-spectrum but the first class of cephalosporins exhibits an antimicrobial spectrum that was particularly active against gram-positive bacteria. Minimum Inhibitory Concentration (MIC) determination results of cefadroxil showed that all types of bacteria could be inhibited primarily gram positive bacteria, but the Minimum Inhibitory Concentration (MIC) value on gram-positive bacteria (Staphylococcus epidermidis), cefadroxil has a higher than gram-positive bacteria (Staphylococcus aureus). Increased of Minimum Inhibitory Concentration (MIC) of cefadroxil on Staphylococcus epidermidis have been due to bacteria have experienced resistance. Resistance to cefadroxil due to bacteria have formed a $\beta$-lactamase enzyme that could degrade the drug, it was caused drug levels that should inhibit cell wall synthesis was reduced, so the effects of antibiotic to bacteria were reduced. The 1,5-bis (3'-ethoxy-4'-hydroxyphenyl)-1,4-pentadiene-3-one have the same antibacterial activity in both gram-positive and gram-negative bacteria with the same Minimum Inhibitory Concentration (MIC) value of $0.15 \mathrm{ppm}$, even in staphylococcus aureus and escherichia coli, in previously reported the 1,5-bis (3'-ethoxy-4'-hydroxyphenyl)-1,4pentadiene-3-one have better antibacterial activities than antibacterial activities of curcumin $[17,18]$. This indicated that 1,5 -bis $(3 '$-ethoxy-4'hydroxyphenyl)-1,4-pentadiene-3-one has a broad spectrum as antibacterial, this was related to the lipophilicity of 1,5-bis (3'-ethoxy-4'hydroxyphenyl)-1,4-pentadiene-3-one. Subtitued of the methoxy group on curcumin with ethoxy groups have made 1,5-bis (3'-ethoxy-4'hydroxyphenyl)-1,4-pentadiene-3-one have higher lipophilicity than curcumin, amoxicillin, and cefadroxil, in addition to steric properties was also greater. The large lipophilicity of 1,5-bis (3'-ethoxy-4'hydroxyphenyl)-1,4-pentadiene-3-one has allows 1,5-bis (3'-ethoxy-4'hydroxyphenyl)-1,4-pentadiene-3-one to diffuse in gram-negative bacteria cell walls that composed of lipopolysaccharides, lipoproteins, and phospholipids. The steric properties have facilitated 1,5-bis (3'ethoxy-4'-hydroxyphenyl)-1,4-pentadiene-3-one to put physical pressure on gram-positive cell walls [19,20].

\section{The diameter of inhibition zone}

Determination of diameter of inhibition zone aimed to determine the sensitivity of bacterial testing of 1,5-bis (3'-ethoxy-4'hydroxyphenyl)-1,4-pentadiene-3-one characterized by the presence of clear zones around the disc (fig 7). The tests were performed on 1,5-bis (3'-ethoxy-4'-hydroxyphenyl)-1,4-pentadiene3-one, amoxicillin and cefadroxil. To determine the diameter of inhibition zone of 1,5-bis (3'-ethoxy-4'-hydroxyphenyl)-1,4pentadiene-3-one, amoxicillin and cefadroxil to the test bacteria were tested by disc diffusion method with some predetermined concentration. The clear zone of 1,5-bis (3'-ethoxy-4'hydroxyphenyl)-1,4-pentadiene-3-one to the test bacterias were average of $11 \mathrm{~mm}$ for all test bacteria. The diameter of Inhibition Zone value of $10-16 \mathrm{~mm}$ indicates moderate activity as antibacterial [23]. While the diameter of inhibition zone of amoxicillin and cefadroxil showed the varied results of each test bacteria, this difference occurs because of the antimicrobial spectra of each derivative varies although the mechanism of action was the same i. e inhibiting cell wall growth (table 2).

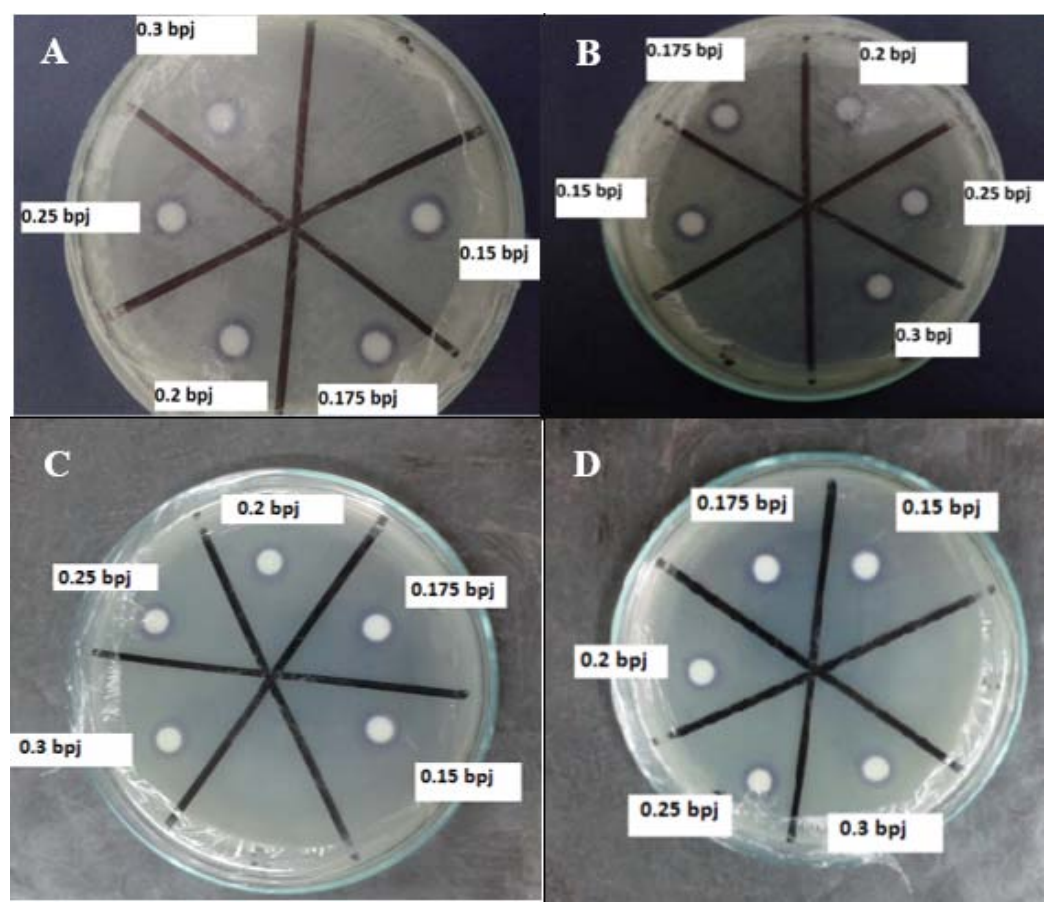

Fig. 7: Diameter of inhibition zone of 1,5-bis (3'-ethoxy-4'-hydroxyphenyl)-1,4-pentadiene-3-one (A) Staphylococcus aureus (B) Staphylococcus epidermidis, (C) Escherichia coli, (D) Salmonella thypi 
Table 2: Diameter of inhibition zone (mm)

\begin{tabular}{llll}
\hline & \multicolumn{2}{l}{ Diameter of inhibition zone* (mm) } \\
\hline Test compound & $\begin{array}{l}\text { Staphylococcus } \\
\text { aureus } \text { (ATCC 6538) }\end{array}$ & $\begin{array}{l}\text { Staphylococcus } \\
\text { epidermidis } \text { (ATCC 12228) }\end{array}$ & $\begin{array}{l}\text { Escherichia coli } \\
\text { (ATCC 25922) }\end{array}$ \\
\hline 1,5-bis (3'-ethoxy-4'-hydroxyphenyl)- & & & $\begin{array}{l}\text { Salmonella thypi } \\
\text { (ATCC 14028) }\end{array}$ \\
1,4-pentadiene-3-one & $11.27 \pm 0.31$ & $11.35 \pm 0.39$ & $11.25 \pm 0.33$ \\
Amoxicillin & $8.22 \pm 0.25$ & $8.07 \pm 0.38$ & $7.23 \pm 0.32$ \\
Cefadroxil & $8.33 \pm 0.33$ & $6.7 \pm 0.17$ & $7.52 \pm 0.28$ \\
\hline
\end{tabular}

$*$ Means \pm SD, $\mathrm{n}=3$

The diameter of inhibition zone that obtained of 1,5-bis (3'-ethoxy-4'hydroxyphenyl)-1,4-pentadiene-3-one was reproduced against test bacteria compared with $\beta$-lactam group antibiotics have been analyzed using statistical data processing program. Statistical analysis was done to determine normality and homogeneity of data. The test results obtained normal distributed and homogeneously distributed with pvalue $>0.05$. The one-way ANOVA parametric test was done to determine the difference of diameter of inhibition zone of 1,5-bis (3'ethoxy-4'-hydroxyphenyl)-1,4-pentadiene-3-one compared to the $\beta$ lactam group antibiotics. It was obtained significance value of $\mathrm{p}=$ $0.000(\mathrm{p}<0.05)$. It meant there was a significant difference between 1,5-bis (3'-ethoxy-4'-hydroxyphenyl)-1,4-pentadiene-3-one and $\beta$ lactam group antibiotic [28]. From the results obtained that the 1,5-bis (3'-ethoxy-4'-hydroxyphenyl)-1,4-pentadiene-3-one has better antibacterial activity compared with $\beta$-lactam group antibiotics. This difference may occur because 1,5 -bis ( 3 '-ethoxy-4'-hydroxyphenyl)1,4-pentadiene-3-one has a stronger mechanism of action as inhibitors of cell wall synthesis. The cell wall of the bacterial class contains thin peptidoglycan and the remaining proteins, lipopolysaccharides, and lipoproteins, so the 1,5-bis (3'-ethoxy-4'-hydroxyphenyl)-1,4pentadiene-3-one could disrupt the synthesis of cell wall formation and could cause cell lysis, then cause death in microbial cells.

\section{CONCLUSION}

The 1.5-bis (3'-ethoxy-4'-hydroxyphenyl)-1,4-pentadiene-3-one as curcumin analog compounds have biological activity as antibacterial. The antibacterial activity of 1,5-bis (3'-ethoxy-4'-hydroxyphenyl)1,4-pentadiene-3-one was stronger than the $\beta$-lactam group antibiotics both amoxicillin and cefadroxil. Based on Minimum Inhibitory Concentration (MIC) and diameter of inhibition zone, 1,5bis (3'-ethoxy-4'-hydroxyphenyl)-1,4-pentadiene-3-one has strong antibacterial activity in both gram-positive and gram-negative bacteria. An in vitro evaluation was in line with in silico evaluation that showed the 1,5-bis (3'-ethoxy-4'-hydroxyphenyl)-1,4pentadiene-3-one has the lowest docking score.

\section{ACKNOWLEDGEMENT}

Thanks to the Director-General for Strengthening Research and Development, Kemen Ristek Dikti as a fund grant for the implementation of this research.

\section{AUTHORS CONTRIBUTIONS}

All of the authors designed, directed the project and contributions on wrote the article; on experiment work, Purwangga performed the in vitro experiment, Mumpuni performed the synthesis and characterized 1,5-bis (3'-ethoxy-4'-hydroxyphenyl)-1,4-pentadiene3-one, Mulatsari performed the in silico experiment.

\section{CONFLICTS OF INTERESTS}

All authors have none to declare

\section{REFERENCES}

1. McGhie EJ, Brawn LC, Hume PJ, Humphreys D, Koronakis V. Salmonella takes control: effector-driven manipulation of the host. Curr Opin Microbiol 2009;12:117-24.

2. Hai-long Z, Shimin C, Yalan L. Some Chinese folk prescriptions for wind-cold type common cold. J Tradit Complement Med 2015;5:135-7.

3. Sun Q, Liu L, Wu L, Li W, Liu Q Zhang J, et al. Web resources for microbial data. Genomics Proteomics Bioinf 2015;13:69-72.
4. Daniel M, Musher MD, Thorner AR. Community-acquired pneumonia. N Engl J Med 2014;371:1619-28.

5. Dormond L, Jaton K, de Valliere S, Genton B, Greub G. Malaria real-time PCR: correlation with clinical presentation. New Microbes New Infect 2015;5:10-2.

6. Andrews KT, Fisher G, Skinner-Adams TS. Drug repurposing and human parasitic protozoan diseases. Int J Parasitol Drugs Drug Resist 2014;4:95-111.

7. Ortayli N, Ringheim K, Collins L, Sladden T. Sexually transmitted infections: progress and challenges since the 1994 international conference on population and development (ICPD). Contraception 2014;90 Suppl 6:S22-S31.

8. Giedraitinene A, Vitkauskiene A, Naginiene R, Pavilonis A. Antibiotic resistance mechanisms of clinically important bacteria. Medicina (Kaunas) 2011;47:137-46.

9. Tyagi P, Singh M, Kumari H, Kumari A, Mukhopadhyyay K. Bactericidal activity of curcumin I is associated with damaging of bacterial membrane. Plos One 2015;10:e0121313. Doi:10.1371/journal.pone.0121313.

10. Kali A, Bhuvaneswar D, Charles PMV, Seetha KS. Antibacterial synergy of curcumin with antibiotics against biofilm producing clinical bacterial isolates. J Basic Clin Pharm 2016;7:93-6.

11. Teow S, Liew K, Ali SA, Khoo AS, Peh SC. Antibacterial action of curcumin against staphylococcus aureus: a brief review. J Trop Med 2016:1-10. http://dx.doi.org/10.1155/2016/2853045

12. Liang G, Yang S, Jiang L. Synthesis and anti-bacterial properties of mono-carbonyl analogues of curcumin. Chem Pharm Bull 2008;56:162-7.

13. Pandey A, Gupta RK, Bhargava A, Agrawal B. Antibacterial activities of curcumin bioconjugated. Int $\mathrm{J}$ Pharmacol 2011;7:874-9.

14. Hamed OA, Mehdawi N, Taha AA, Hamed EM, Al-Nuri MA, Hussein AS. Synthesis and antibacterial activity of novel curcumin derivatives containing heterocyclic moiety. Iran J Pharm Res 2013;12:47-56.

15. Muhamed $\mathrm{H}$, Jayandran $\mathrm{M}$, Balasubramanian V. Evaluation of antimicrobial activity of green-synthesized manganese oxide nanoparticles and comparative studies with curcuminaniline functionalized nano form. Asian J Pharm Clin Res 2017;10:347-52.

16. Mumpuni E, Indriana P, Sulastri E, Rusnawan E. Synthesis and antioxidant test of 1.5-bis (3'ethoxy-4'-hydroxyphenyl)-1,4pentadiene-3-one (EHP). JIFI 2010;8:91-100.

17. Mumpuni E. Microwave assisted organic synthesis of 1,5-bis (3'-ethoxy-4'-hydroxyphenyl)-1,4-pentadien-3-one (EHP) compound, the inhibition of COX-2 in silico test and the pharmacological activity test. Dissertation. Gadjah Mada University, Indonesia; 2016.

18. Mumpuni E, Rahayu L, Nurrochmad A. Toxicity and antiinflammatory effect of 1,5-bis(3'-etoksi-4'-hidroksifenil)-1,4pentadien-3-one compound. JIFI 2015;13:45-9.

19. Departement of pharmacology and therapeutic. Pharmacology and Terapy. $5^{\text {th }}$ ed. Jakarta: Medical faculty, University of Indonesia; 2007.

20. Qin $\mathrm{W}$, Panunzio M, Biondi S. $\beta$-Lactam antibiotics renaissance. Antibiotics 2014;3:193-215.

21. Maulana T, Purnomo H. Tea leaves extracted as anti-malaria based on molecular docking PLANTS. Procedia Environ Sci 2013;17:188-94.

22. Mulatsari E, Mumpuni E. Vitual screening and binding mode elucidation of curcumin analogues on cyclooxygenase-2 using AYO_COX2_V1.1 protocol. J Physics Conf Series 2017;835:1-7. 
23. Aniyeri RB, Gupta A, Singh $\mathrm{P}$, Sanju. In vitro and in silico antimicrobial study of stannane of pyridoxal 5-phosphate. Int J Pharm Pharm Sci 2017;9:145-53.

24. Warren, Stuart. Organic synthesis: the disconection approach, John Wiley and Sons, Chicester; 2008.

25. Korb 0, Stutzle T, Exner TE. Empirical scoring functions for advanced protein-ligand docking with PLANTS. J Chem Inf Model 2009; 49:84 - 96

26. Kumar KM, Anitha P, Sivasakthi V, Bag S, Lavanya P, Anbarasu $\mathrm{A}$, et al. In silico study on penicillin derivatives and cephalosporins for upper respiratory tract bacterial pathogens. 3 Biotech 2014;4:241-51.

27. Balavignesh V, Srinivasan E, Ramesh Babu NG, Saravanan N. Molecular docking study on NS5B polymerase of hepatitis c virus by a screening of volatile compounds from acacia concinna and ADMET prediction. Int J Pharm Life Sci 2013;4:2548-58.

28. Wulansari A, Jufri M, Budianti A. Studies on the formulation, physical, stability, and in vitro antibacterial activity of tea tree oil (melaleuca alternifolia) nanoemulsion gel 2017:9 Suppl 1:135-9. 